\title{
Article
}

\section{Development of a Cross-Disciplinary Investigative Model for the Introduction of Microarray Techniques at Non-R1 Undergraduate Institutions}

\author{
David E. Walker, ${ }^{*}$ Gary P. Lutz, ${ }^{\dagger}$ and Consuelo J. Alvarez ${ }^{\ddagger}$
}

${ }^{*}$ College of Dental Medicine, Nova Southeastern University, Fort Lauderdale, FL 33328-2018; ${ }^{\dagger}$ Prince Edward County High School, Farmville, VA 23901; and ${ }^{\ddagger}$ Department of Biological and Environmental Science at Longwood University, Farmville, VA 23909

Submitted January 31, 2007; Revised October 9, 2007; Accepted November 5, 2007

Monitoring Editor: Mary Lee Ledbetter

\begin{abstract}
Integrating advanced biological techniques into instruction at non-R1 institutions can prove to be a challenge. Here, we report the creation of a model for the introduction of gene expression microarray technology into a research laboratory. A student assessment tool was used to evaluate 1) technical skill development, 2) cross-disciplinary issues, 3) development of trouble-shooting skills, and 4) career evaluation. The exposure of Saccharomyces cerevisiae yeast cells to three plasticizers served as a template for the introduction of this technology. Cells were harvested at mid-log phase, and RNA was extracted. The mRNA was converted to cDNA by using reverse transcriptase primers containing a capture sequence that was later recognized by a fluorescent dendrimer by using cyanine (Cy) 3 or Cy5 dyes. cDNA was hybridized onto yeast microarray chips provided by the Genome Consortium for Active Teaching. Exposure to phthalate plasticizers revealed genes with differential gene expression. Trouble-shooting approaches were used as learning opportunities for the evaluation of RNA extraction methods, and data analysis highlighted the use of mathematics in a molecular biology context. This article describes a promising model for the introduction of interdisciplinary, student-based projects involving microarray technology at non-R1 undergraduate institutions.
\end{abstract}

\section{INTRODUCTION}

With the ever-increasing abundance of genomic information, working with technologies that investigate gene function is becoming more prevalent in graduate experiences in molecular biology. The advent of gene expression microarray analysis has allowed researchers to move away from traditional genetics research where one gene is studied at a time. Instead, an entire genome can be evaluated simultaneously, and potential interactions among genes can be investigated.

As microarray analysis becomes more widely used, the potential for microarray technology to become an analytical tool that graduate students and researchers use routinely also will increase (Fehrenbach et al., 2003; Grigoryev et al.,

DOI: $10.1187 /$ cbe.07-01-0006

Address correspondence to: Consuelo J. Alvarez (alvarezcj@ longwood.edu).
2004; Arnaud, 2006). As such, the introduction of a sophisticated tool such as microarray analysis into an undergraduate program in molecular biology represents a valuable learning opportunity for undergraduate students considering a career in molecular biology research or in medical fields.

The introduction of hands-on activities involving gene expression microarray technology into the routine laboratory curricula of undergraduate programs in biology can be problematic, and it may not be practical at some non-R1 institutions. Teaching genomic concepts by introducing gene expression microarray technology into an undergraduate research environment represents an attractive alternative. The Genome Consortium for Active Teaching (GCAT) provides valuable support for institutions wishing to introduce microarray analysis concepts to undergraduate students (Campbell et al., 2006). Examples of support provided to undergraduate faculty by the consortium are as follows: 1) workshops on techniques in gene expression analysis, 2) 
access to significantly less expensive microarray chips, 3) labor and equipment to scan microarray chips in a timely manner, and 4) electronic access to the data from the scanned chips. Undergraduate faculty wishing to use the support offered by GCAT must ensure that all students exposed to the microarray techniques complete an assessment and report all data to assist in the evaluation of learning related to microarray analysis technology.

Longwood University in Farmville, VA, is a state-funded liberal arts university, and it has a long tradition as a teacher preparatory institution. The creation of a research environment that allows students to experience what research may be like during graduate school is a vital component of the overall mission of the university. We have created a model for the introduction of microarray technology into a crossdisciplinary research environment at this non-R1 undergraduate institution. At the start of the 2007 spring semester, of $\sim 680$ undergraduate candidates for graduation, 35 were candidates for a degree in biology, five in mathematics, and three in chemistry.

Some aspects of laboratory work with microarray projects require planning by both students and faculty to fit into student class and work schedules and faculty teaching schedules. Moreover, the mentoring nature of the research model being presented requires that the faculty member work closely with student researchers. To find the requisite blocks of time, we often began experiments as early as $6 \mathrm{AM}$, and we conducted experiments over weekends or during academic recesses. To facilitate scheduling, students were given complete access to the laboratory and to a projectdesignated computer.

The goals of the work reported here include the following: 1) creating a cross-disciplinary, student-based research program in molecular biology that incorporates genomic information; 2) exploiting trouble-shooting methods as tools for development of problem-solving and critical-thinking skills; 3) providing a research-based environment wherein students can develop skills using sophisticated new techniques in molecular biology; and 4) allowing students to evaluate potential interest in a career in molecular biology research.

When introducing a sophisticated technique into research at a non-R1 institution, one of the first priorities is to attract highly motivated students. Attracting such students is essential because successful completion of experiments will occur only when proper care and attention to detail are applied throughout the experimental process. Students working with sophisticated new technologies will typically be required to make commitments of time and effort beyond the expectations of many of their peers. In large departments where significant numbers of students are bound for graduate school each year, finding students willing to participate in learning activities in research will not likely be difficult. At smaller universities, the task may be formidable depending upon the level of emphasis that students place on research. Students at Longwood University are required to complete only one credit of research or internship for graduation.

At Longwood University, students who excel in a class such as organic chemistry are often well suited to carry out molecular biology research. At institutions with relatively small chemistry departments, biology students often make up the majority of the organic chemistry class. When the focus in the organic chemistry classroom is on integration and application of ideas (Uno, 1990), students who perform well typically have superior problem-solving skills and are more adaptable to the changing requirements that learning in a research environment requires. Biology students who have the ability and motivation to excel in organic chemistry have been the strongest candidates for participating in molecular biology projects at Longwood University. Most of these students are pursuing potential careers in a medically related field or in a graduate program in biology, so working on a research project using gene expression microarray technology adds an opportunity for self-evaluation related to career options.

Many science students in their first year have only vague ideas about potential career plans. Many aspire to careers in health-related disciplines. Course work in a selected major slowly helps to solidify plans for some students. An important goal of the undergraduate research model reported here is that it provides an environment wherein students at an early stage in their undergraduate experience develop critical-thinking skills and creates an occasion for self-evaluation. As such, this model provides students with the opportunity to 1) influence the direction of a research project, 2) work with one or more sophisticated techniques that are being used in graduate and professional research centers, 3) collaborate with faculty and students in other disciplines, and 4) evaluate and improve work they complete.

Students considering careers in medical fields or graduate school frequently have multiple commitments outside of the classroom that affect the amount of time they are able to devote to work on research activities. At Longwood University, students work at hospitals, clinics, and pharmacies, or with veterinarians as part of the process required for gaining acceptance into professional programs. Other students work to earn sufficient money to stay in school. As a result, some highly motivated undergraduate students have limited opportunities to participate in meaningful research activities. At Longwood, microarray research projects involving chemical and environmental stressors that provide students with an opportunity to gain experience in one or more techniques are appealing.

Students investigating potential effects of chemical stressors using microarray analysis techniques gain expertise in fundamental components of several different biology classes within typical biology programs. Because baker's yeast is used as a study organism, students learn how to store, grow, and save liquid cultures and yeast plates. Furthermore, working under sterile conditions, the students learn to operate an autoclave and to sustain media and cell cultures free of air-borne contaminants. Students also learn to monitor cell growth by using a microscope and a spectrophotometer. After working through the issues related to growing viable cells, students then expose cells to the stressors of interest. At this point, skill development related to the manipulation of RNA and DNA begins. Obtaining quality RNA is essential, and it requires a thorough understanding of molecular biology techniques to trouble-shoot for problems and to alter the procedures to fit the working environment in the laboratory. All of these aspects provide students with opportunities to develop critical-thinking skills and the ability to manipulate each piece of equipment used in a modern molecular biology environment. 
For microarray data analysis, additional skills related to bioinformatics and statistical analysis are developed. The incorporation of data analysis into a project provides potential additional projects for mathematics students. Collaboration and teamwork skills can be developed among biology, chemistry, and mathematics students (Tanner et al., 2003; National Institute for Science Education, 2003). Using microarray analysis as a teaching tool in research thus provides a platform to impact student learning related to problem solving, critical thinking, teamwork, the relationship between theory and practice, time management in the laboratory, and career path evaluation.

In the context of this research model, students involved with microarray analysis are involved in the decision-making process regarding areas to investigate and in analysis of the results from all experiments. The enthusiasm of a predental biology major for organic chemistry, an organic chemist's interest in learning about ways to investigate the impact of plasticizers on health, and a biochemist's interest in introducing hands-on microarray technology to Longwood University students led to the creation of this project investigating the effects of plasticizers on gene expression by using microarray analysis.

A plasticizer is any molecule that, when added to a polymer, aids in keeping the polymer soft, pliable, or both. Plasticizers are used by the millions of tons, and they are components of a vast number of everyday plastic items ranging from car parts to medical supplies to children's toys. The potential effect of plasticizers on health is a topic that is debated in public forums. Fear continues to be expressed that one class, phthalate esters, can function as hormone mimics (Soto et al., 1995). Some investigations of phthalate ester plasticizers focus on identifying statistical differences in the health of workers in industries where phthalate ester plasticizers are used or are produced (Roberts, 1983; Fracasso et al., 1999). Other research has attempted to quantify exposure to phthalate ester plasticizers in the general population (Caldwell et al., 1998; Chan and Meek, 1994; Meek and Chan, 1994; Molhave et al., 2000; Mikula et al., 2005). Still other investigations are involved with testing the effects of phthalate ester plasticizers on plant or animal development (Kambia et al., 2004; Mahood et al., 2005; Huang et al., 2006; Saillenfait et al., 2006; Sobarzo et al., 2006). A project using microarray techniques to evaluate the effects of potentially harmful chemicals on cell function can create a research environment wherein students feel enthusiastic about working on a project that is socially and scientifically relevant.

In 1977, Shahin and Von Borstel tested the survival rates of exposed yeast cells to phthalates esters for different periods (Shahin and Von Borstel, 1977). Their results revealed $62-67 \%$ survival rates in $6 \mathrm{~h}$ of exposure. However, their work was not a molecular study; thus, further learning using microarray techniques may lead to an identification of specific genes involved in cell repair systems. Based on the hypothesis that stressed cells will activate repair systems and that activation of repair systems will potentially alter gene expression, exposure of cells to phthalate esters at the levels of Shahin and Von Borstel's investigation is likely to produce changes in gene expression in our study.

Once data are successfully obtained from the laboratory work associated with such a microarray project, the scope of the project can be easily broadened to incorporate students and faculty in mathematics. Projects related to mathematical evaluation methods of microarray data will be a focus area for our future work.

\section{MATERIALS AND METHODS}

All plasticizers were obtained from commercial sources. Di-(2-ethylhexyl)-phthalate (DEHP), also known as dioctyl phthalate because a 2-ethylhexyl group has eight carbon atoms in the chain, was obtained from Sigma-Aldrich (St. Louis, MO; catalog no. 525154); dibutyl phthalate (DBP) was obtained from Fisher Scientific (Pittsburgh, PA; catalog no. AC16660-0010); and the epoxidized soybean oil (ESBO) was obtained from Fluka (St. Louis, MO; catalog no. 43956). All plasticizers were used as obtained from the distributor without further purification. MasterPure Yeast RNA Purification kit was obtained from Epicenter Technologies (EPI; Madison, WI; catalog no. MPY03100). The 3DNA 350 kit was obtained from Genisphere (Hatfield, PA; catalog no. W300180).

\section{Cell Preparation}

The Saccharomyces cerevisiae yeast strain X2180-1A was kindly provided by Dr. Kirk Anders (Department of Genetics, Stanford University School of Medicine). A full loop of cells (from a sample stored at $-80^{\circ} \mathrm{C}$ ) was inoculated in a $5.0-\mathrm{ml}$ aliquot of sterile liquid media, and cells were allowed to grow at $30^{\circ} \mathrm{C}$ in a shaking water bath. The liquid media is made up of $10 \mathrm{~g}$ of yeast extract, $20 \mathrm{~g}$ of yeast peptone, and $20 \mathrm{~g}$ of dextrose for a 1-liter volume (YPD media). Once a cell culture reached an optical density of 2 at $600 \mathrm{~nm}$ (usually overnight, $\sim 12 \mathrm{~h}$ ), a $300-\mu l$ sample was diluted to a total volume of $5 \mathrm{ml}$ with fresh YPD media and incubated overnight to obtain a cell culture with an optical density of approximately $0.2-0.3$. For the investigation of DEHP and DBP, three separate samples were used: a control not exposed to plasticizer, a "low plasticizer" sample to which $25 \mu \mathrm{l}$ of plasticizer was added (final concentration $5 \mathrm{ng} / \mathrm{ml}$ ), and a "high plasticizer" sample with $50 \mu \mathrm{l}$ of plasticizer (final concentration $10 \mathrm{ng} / \mathrm{ml}$ ) (Shahin and Von Borstel, 1977). For the ESBO plasticizer, only control and low plasticizer samples were used. All samples were grown at $30^{\circ} \mathrm{C}$ in a shaking water bath until the control sample attained an optical density at $600 \mathrm{~nm}$ of $1.1, \sim 5.0 \mathrm{~h}$.

\section{Total RNA Extraction}

Total RNA was isolated by using a modified version of the MasterPure Yeast RNA Purification kit (EPI). The modified version of the procedure is provided in Supplemental Material A. In the RNA Purification section of the protocol, the initial amount of yeast cells used for RNA extraction was increased. The volume was changed from 1.0 to $1.5 \mathrm{ml}$ to $2 \mathrm{ml}$. In addition, the length of the incubation period was increased from 10 to $15 \mathrm{~min}$ to $30 \mathrm{~min}$. The optional Removal of Contaminating DNA from RNA Preparations section of the protocol was always used, and the incubation period was increased to $30 \mathrm{~min}$. RNA sample integrity was assessed by running $0.3-0.5 \mu \mathrm{l}$ of each sample in a $0.8 \%$ agarose gel prepared with Tris-acetate-EDTA buffer with $\lambda$ HindIII DNA molecular weight markers. The RNA concentration, $1.0-1.5 \mu \mathrm{g} / \mu \mathrm{l}$, is estimated by staining with ethidium bromide and comparing the result with standards produced with known quantities of molecular markers. The remaining aqueous RNA suspension $(\sim 12 \mu \mathrm{l})$ was stored at $-20^{\circ} \mathrm{C}$ until use the next day for cDNA preparation.

\section{cDNA Preparation and Hybridization}

The Genisphere 3DNA 350 kit protocol was used without modification. The option of using vial 7 ( $2 \mathrm{X}$ formamide-based hybridization buffer) was always chosen. The complete protocol can be found on the GCAT website (http://www.bio.davidson.edu/projects/ gcat/protocols/3DNAmethod.doc). 


\section{Yeast Microarray Chips: Source and Scanning}

Microarray chips were purchased from GCAT. All microarray chips are 70mer oligonucleotides printed on epoxy slides. Chip 06185 used for DBP was produced by the Institute for Systems Biology (ISB) at Seattle, WA, and contains 27,648 potential gene locations (including all of the controls). All other chips used were produced by Washington University at St. Louis, MO. The identification numbers of the chips from Washington University are as follows: 1, 4, 5, 7 , and 8 for DBP; 12, 13, 14, and 15 for DEHP; and 43 and 871 for ESBO. All of these chips contain 14,784 potential gene locations (locations for all of the controls are included). Scans of the DNA chips after completion of the exposure experiments were performed at the Biology Department of Davidson College at Davidson, NC, by using the scanner model ArrayWoRx ${ }^{\mathrm{e}}$ manufactured by Applied Precision (Issaquah, WA). For details related to sending chips and retrieval of data, refer to GCAT (2006a).

\section{Data Analysis}

The computer program MAGIC Tool (Heyer et al., 2005) was used to obtain the data from the scanned chips. The program, tutorial, and instruction manual are available free of charge at http://www.bio. davidson.edu/projects/magic/magic.html.

MAGIC Tool retrieves the scanned images and the gene list that contains the order in which the genes are printed on a chip. For Gene List information, refer to GCAT (2006b). Each chip used produces two images, one image for the fluorescent dendrimer by using cyanine (Cy) 3 dye scanned at $595 \mathrm{~nm}$ and the second image for the fluorescent dendrimer by using Cy 5 dye scanned at $685 \mathrm{~nm}$. The resulting data are stored as black-and-white images, and MAGIC Tool converts them into color images that range from green (predominantly Cy3 dye) at one end of the spectrum, through yellow (approximately equal for both dyes) to red (predominantly Cy5 dye) at the other end of the spectrum. The fluorescent dendrimer obtained by using $\mathrm{Cy} 3$ dye (green) was always used with the control RNA, and the fluorescent dendrimer obtained using Cy5 dye (red) was always used for the sample exposed to a plasticizer. The possibility exists that consistently exposing the control RNA to only the Cy3 dye and the experimental sample to the Cy5 dye may introduce a "dye bias." Future experiments where the exposure to the dyes is reversed need to be performed to fully evaluate this potentiality.

Therefore, for any given gene location on the grid, a green image indicated that a gene was expressed in the normal condition and that repression may have occurred. A red image indicated that a gene was expressed in the stressed environment and that induction may have occurred. Expression ratios were computed as red/green. A yellow image indicated that genes in both samples, control and stressed, were affected in a similar manner. "Addressing" was accomplished by assigning the number of grids on the particular chip and the number of rows and columns in each grid. All chips contained two duplicate metagrids. Chip 06185 contained 24 grids in each metagrid, and each individual grid contained 24 columns and 24 rows. The remaining chips contained 16 grids in each metagrid, and each individual grid contained 22 columns and 21 rows. For more details about "addressing/gridding/segmentation," refer to the MAGIC Tool instruction manual (http://www.bio. davidson.edu/projects/magic/magic.html).

The expression file may be saved either as an "exp" expression file or as a "raw" expression file. The exp files are useful within the framework of the MAGIC Tool program. The raw expression files can be used for manual evaluation within the Microsoft Excel program, and they provide readily available information related to signal intensity that is not easily accessible with the exp files. To illustrate how initial data analysis can be accomplished, the following data manipulations were performed. One possible filtering process excludes gene locations with total intensities (threshold intensities) of $<200,500$, or 1000 where the intensity value being compared with the threshold value represents intensity data from the column labeled "red foreground total" plus intensity data from the column labeled "green foreground total" in the raw expression file. Higher threshold values represent more stringent filtering conditions. The ratio of data in the column labeled red foreground total divided by data from the column labeled green foreground total was used to evaluate potential induction or repression. Data were further filtered by requiring that the intensity ratios were greater (or less than the inverse of) a prescribed value. The value used for comparison is called the fold, and fold values of 2 or 3 are common (DeRisi et al., 1997). Here, potential induction was indicated by having a ratio of 3 or greater for a given gene location in the raw expression file. Potential repression was indicated by having a ratio of red to green intensity of $<0.3333$ (the inverse of the fold value of 3) for a given gene location in the raw expression file. Using a greater fold value represents a more stringent filtering process. Data that satisfied the threshold intensities and fold repression or induction described above were log base 2 transformed before continuing the analysis. Statistically significant genes were also identified by the computer program Significant Analysis of Microarray (SAM) and compared with the data obtained using the MAGIC Tool data analysis options. For academic users, the SAM program, user guide, and technical documents are available free of charge at http:// www-stat.stanford.edu/ tibs/SAM/index.html.

\section{RESULTS AND DISCUSSION}

Cells are known to repair themselves when exposed to diverse stresses that alter homeostasis. Because exposure to potentially harmful chemical stressors may produce observable changes in cell function, microarray techniques may prove useful in estimating potential health effects of a wide range of chemical stressors, from impending pharmaceuticals to latent toxins. The baker's yeast cells, S. cerevisiae, were chosen as a model eukaryotic system (Verma and Singh, 2001) for exposure to chemical stressors because yeast cells use a similar mechanism to coordinate DNA repair as human cells and because of the common use of yeast cells in genetic research.

DEHP along with DBP are two phthalate ester plasticizers used in the current study. DEHP is one of the most common phthalate plasticizers, and it is found in many locations in the environment. DBP has applications in dentistry (Munksgaard, 2004) and in children's toys. Cellular exposure to phthalates began with DBP, and three trials were completed at both high and low phthalate concentrations. As student expertise with the microarray methodology increased, the number of trials at each concentration was reduced from three to two.

A class of new plasticizers, purported to be more environmentally benign than phthalate esters, is being introduced into the marketplace. The new class of plasticizers is derived from vegetable oils, and ESBO is one of the most common examples. ESBO was chosen to allow for comparison to the well-established phthalate esters as another method of promoting student awareness of environmental issues. Because initial work with the phthalate esters demonstrated differential gene expression at the low plasticizer concentration, a high plasticizer concentration of ESBO was not investigated.

Learning to identify the true results of a procedure is an essential research skill that is difficult to appreciate fully in classroom-based laboratory activities because of time and resource constraints. A tendency in classroom-based laboratory activities is to provide classes with procedures that are optimized to increase the likelihood of success on the first 
try. Allowing students to learn from failures may initially reduce the overall amount of research that will be completed in a given time frame and increase the cost of the research. As a result, faculty at non-R1 institutions with very limited time for performing career-advancing research may be tempted to "train" research students to perform specific tasks rather than to provide an environment that is more consistent with developing critical-thinking and problemsolving skills. Limitations in research budgets may further exacerbate this situation. In the context of the model being presented here, research students at Longwood University are allowed to have "failures," but they are encouraged to evaluate the failures and to make corrections to the technique or procedure. Although initial investments in both time and cost of reagents is usually greater than normal with research students under these circumstances, students who perform research for multiple semesters typically make such investments pay significant dividends in the form of overall productivity in later semesters.

Our initial research focused on trouble-shooting methods for obtaining quality RNA because meaningful microarray experiments can be completed only when quality RNA is obtained from the cells being exposed to stressors. Initial investigation focused on developing workable RNA extraction protocols. A variety of protocols was attempted, and the potential of each protocol to provide satisfactory RNA was evaluated. For each protocol, multiple attempts were made to encourage development of skill at manipulating equipment and at interpreting the procedure. In each case, the success or failure of an attempted protocol was determined by an electrophoresis gel (a $0.8 \%$ agarose gel) to look for suitable rRNA as indicated by observing two intact and abundant rRNA (26S and 18S) fragments located near 2.3 kilobase pairs in relation to the $\lambda$ HindIII DNA molecular weight markers. An alternative approach for estimating RNA purity and yields by obtaining the $A_{260 / 280}$ ratio is another option for laboratories that are equipped with a UV spectrophotometer with filters suitable for a UV range including 260-280 nm and that can accommodate small-volume samples.
Four RNA extraction protocols were evaluated by Longwood University researchers, and modifications to the most promising protocol were made before suitable RNA was obtained. Each of the extraction protocols evaluated was completed in $<2-3 \mathrm{~h}$ of laboratory work once the cells had reached a state suitable for harvesting. One protocol involving a procedure that used guanidine thiocyanate (GTE) with a phenol and chloroform cleaning step consistently failed to show detectable RNA as determined by the electrophoresis gel (Figure 1a). No attempts were made to modify the protocol because of the consistent failure to detect rRNA. The protocol included in the RNEasy kit (QIAGEN, Valencia, CA) also failed to provide indications that rRNA was being obtained (Figure 1b) and was also abandoned.

A third protocol, specifically for baker's yeast, called Total RNA Safety kit (TRSK), gave limited success (Figure 1c). There were no well-defined rRNA bands present, but there were indications that the protocol was providing some rRNA. Careful examination of the procedure indicated that the cell cultures used for this protocol had been obtained after growing to an optical density of between 1.5 and 2.0 at $600 \mathrm{~nm}$. The protocol was modified to obtain cell cultures that were allowed to grow to an optical density of no more than 1.0 at $600 \mathrm{~nm}$. This modification resulted in an improvement in rRNA, but abundant signal (possible tRNA or degradation products) remained at the bottom of the lane in all trials.

A fourth protocol from a kit called the MasterPure Yeast RNA Purification kit (EPI) gave encouraging results (Figure 1d). Comparison of the results from the EPI kit's protocol to the TRSK protocol resulted in a decision to abandon the TRSK protocol. Even though the EPI kit gave the most encouraging initial results, the results were not satisfactory. Troubleshooting work using the EPI kit led to modifications of the protocol as described in Supplemental Material A. A detailed description of the trouble-shooting work is given to illustrate where significant learning opportunities were provided to students as part of this educational approach.

Using the suggested procedure of the EPI kit failed to provide a sufficient concentration of RNA based on analysis by gel electrophoresis, and the purity/stability of the RNA a. GTE

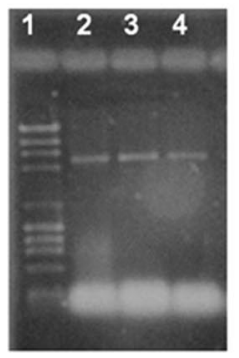

b. Qiagen

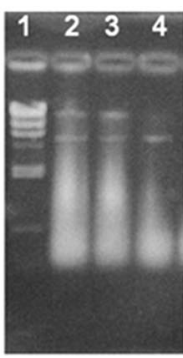

c. TRSK

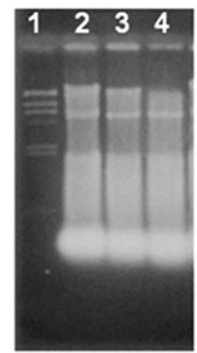

d. EPI

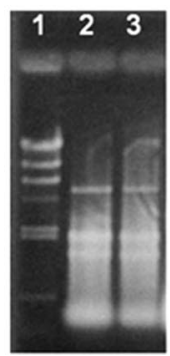

e. EPI with modifications

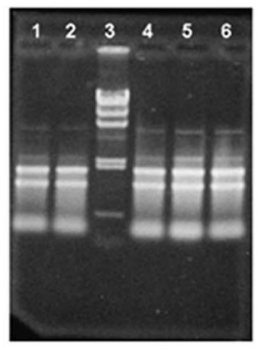

Figure 1. Results from the analysis of trouble-shooting work for total RNA extraction using a nondenaturing $0.8 \%$ agarose gel. The first lane of each panel $(\mathrm{a}-\mathrm{d})$ starting from the left, is for the $\lambda$ HindIII DNA molecular weight size markers $(23-$, 9.4-, 6.6-, 4.4-, 2.3-, 2-, 1-, and 0.6-kilobase pairs, respectively, from top to bottom). For e, these markers are in lane 3 . In a, $\lambda$ HindIII DNA molecular weight markers are mixed with $\phi$ X174 Hae III (23-, 9.4-, 6.6-, 4.4-, 2.3-, 2-, 1.4-, 1-, 0.9-, and 0.6-kilobase pairs, respectively from top to bottom). Other lanes are individual samples from RNA extraction experiments. Each gel was run individually after the extraction was completed, and afterward it was stained with $1 \mu \mathrm{g} / \mathrm{ml}$ ethidium bromide for $10 \mathrm{~min}$. Pictures of the gels were taken with a DS34 Fotodyne Polaroid camera by using a 667 Polaroid black-and-white instant pack film. An indication that the $26 \mathrm{~S}$ and $18 \mathrm{~S}$ rRNA fragments are present is given by obtaining a doublet of bands at the level of 2.3 and 2-kilobase pairs in the size marker's lane. 
obtained proved to be insufficient for a successful microarray experiment. The quantity of rRNA initially obtained is an indication of the quantity of cDNA that will be obtained from the mRNA later. If the initial rRNA concentration is too low, there will be insufficient cDNA to obtain a strong signal when the microarray chips are analyzed. Because the RNA purification section of the protocol most directly affects the amount of RNA that will be obtained, modifications to this part of the procedure were investigated. The two changes to this section of the protocol allowed for a greater quantity of RNA to be extracted. Results indicated that the modifications provided a sufficient increase in RNA concentration to allow for successful completion of the microarray procedure (Figure 1e).

The stability of the RNA obtained from this section of the protocol was also a vital concern because subsequent steps could not always be carried out in a timely manner due to student and faculty scheduling. Therefore, to obtain sufficient purity/stability of the isolated RNA, changes to optional section of the kit's protocol were also investigated. The cleaned RNA preparation was allowed to precipitate in ethanol at $-20^{\circ} \mathrm{C}$ (Alvarez and Wise, 2001). This procedure provided RNA that was stable for at least $2 \mathrm{wk}$. The kit being used is advertised as a rapid method for RNA extraction, but quality RNA was obtained in the current work only when the described modifications were implemented. These modifications nearly double the total time required for the isolation procedure. The unmodified procedure requires $\approx 1 \mathrm{~h}$.

In a further attempt to obtain the strongest signal possible from the cDNA, all work was performed in low light conditions during the entire labeling and hybridization process. This precaution is only explicitly mentioned when working

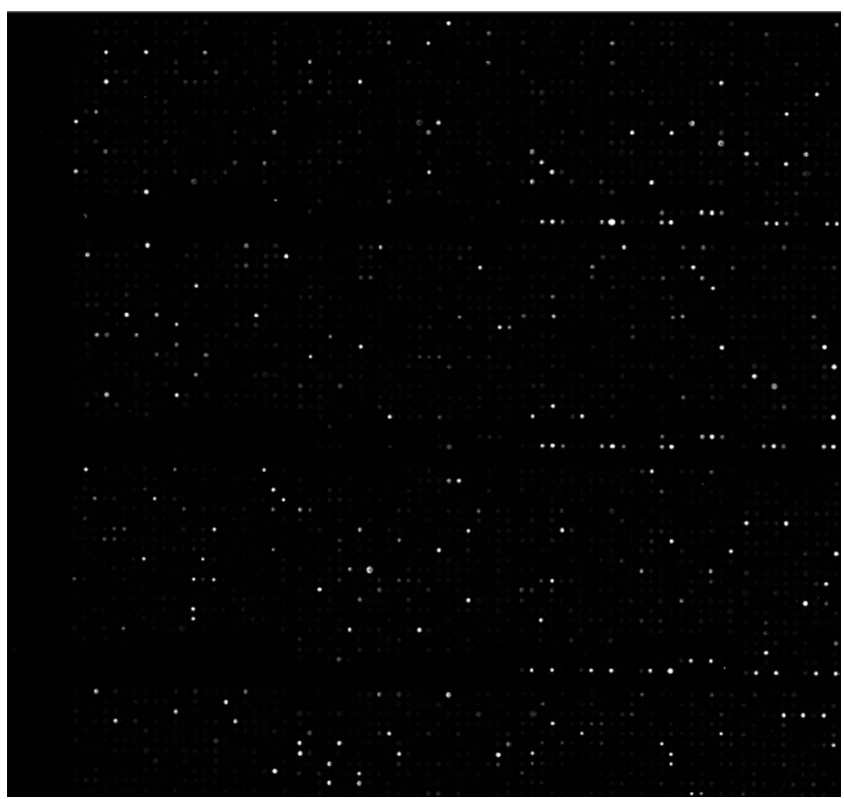

Figure 2. TIFF file retrieved from the ISB server. This image comes from the experiment using chip \#4 with dibutyl phthalate at a $10-\mathrm{ng} / \mathrm{ml}$ concentration scanned at $685 \mathrm{~nm}$ for the fluorescent dendrimer using Cy5 dye. A similar image exists for the fluorescent dendrimer by using Cy3 dye for this experiment scanned at $595 \mathrm{~nm}$. with the capture reagents in the modified Genisphere 3DNA 350 kit protocols provided by GCAT. Although no quantitative data have been obtained to measure the significance of this additional precaution, samples submitted by the laboratory at Longwood University consistently have strong

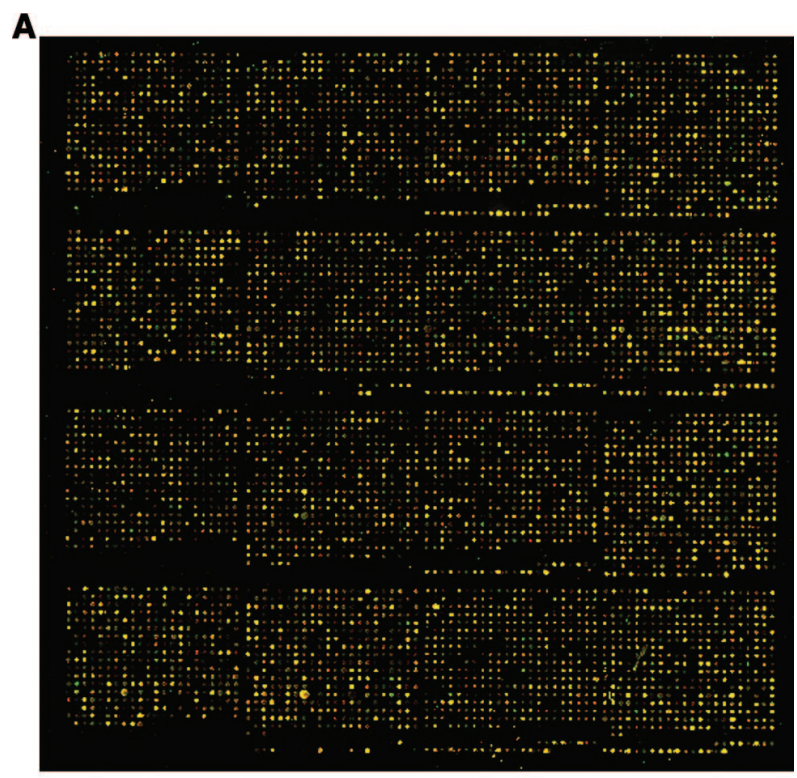

B

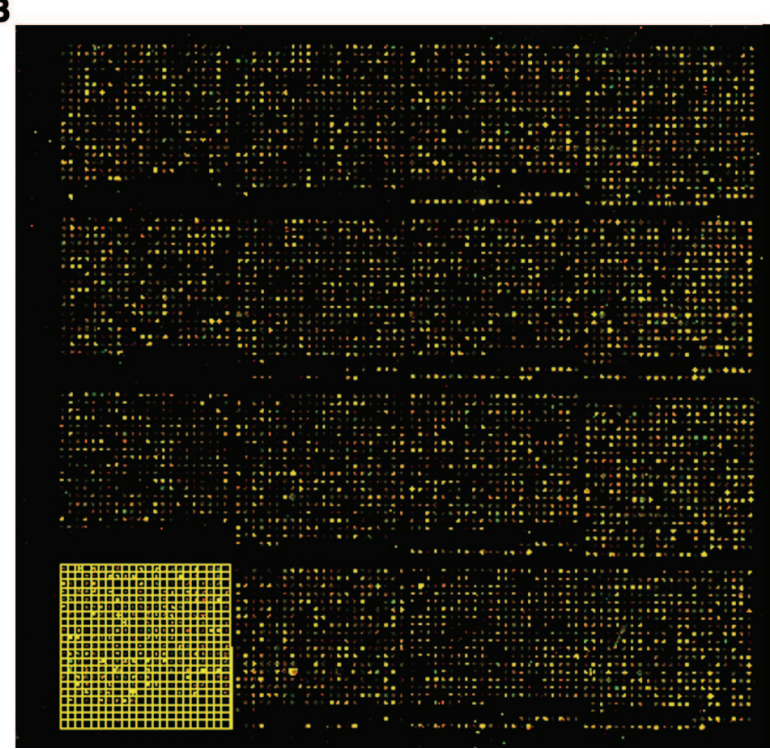

Figure 3. The white spots shown in the image in Figure 2 are converted to color images when the results from scanning for the fluorescent dendrimer by using Cy5 dye are combined with the results from scanning for the fluorescent dendrimer by using Cy3 dye with the MAGIC Tool computer program. (a) Upper metagrid of chip \#4 as obtained using the MAGIC Tool computer program. The metagrid shown contains 16 grids. During the addressing and gridding process, each grid is assigned a number from 1 to 16 from left to right and from top to bottom. (b) Illustration of gridding for grid 13 of the upper metagrid of chip \#4 where the grid has been addressed and is ready for segmentation. Each grid is prepared for segmentation separately. 
intensity signals. Figure 2 shows one of the two initial blackand-white images for a single metagrid on a microarray chip. These images are available via an FTP server provided to GCAT members by ISB. This server is the temporary repository of scanned microarray data that allows public access. The image shown is for the fluorescent dendrimer using Cy5 dye, and a second image for the fluorescent dendrimer by using Cy3 dye (data not shown) is similar. The images in Figure 3A illustrate what a metagrid looks like when the two black-and-white images for a given metagrid have been merged by the MAGIC Tool program. Figure $3 b$ demonstrates the results of addressing and gridding for a single grid within one metagrid. Once each of the grids had been addressed and the gridding was complete for all 32 grids on a single microarray chip, data analysis could begin (except for chip 06185 that contains 48 grids).

It is important to mention that "noise" is an inherent part of microarray data. Factors such as dye effects (Kerr et al.,
2002) or chip manufacturing methods also can contribute to increases or decreases in apparent gene regulation. Collaborators in the mathematics department at Longwood University are currently investigating chip preparation methodology as a potential source of noise in microarray analysis and variations of replicate arrays within the same chips and across chips used in the same experiment.

The data in this report are to meant to serve as the initial stages of analysis and to demonstrate how collaboration with other disciplines such as mathematics and computer science can address issues of whether differential gene expression is statistically significant (Tseng et al., 2001; Tusher et al., 2001). The raw expression data files were first "filtered" to identify grid locations that had red plus green intensity values of $>200,500$, and 1000 . The grid locations above the threshold intensity values were further analyzed to identify locations where potential induction (genes that are turned on in the stressed condition) or repression (genes

Table 1. Results of data filtering analysis

\begin{tabular}{|c|c|c|c|c|c|c|}
\hline Chip no. & Plasticizer & Conc. (ng/ml) & Threshold value & No. above threshold & No. induced & No. repressed \\
\hline \multirow[t]{3}{*}{5} & DBP & 5 & 200 & 10,903 & 2 & 202 \\
\hline & & & 500 & 8991 & 2 & 14 \\
\hline & & & 1000 & 6629 & 2 & 6 \\
\hline \multirow[t]{3}{*}{7} & DBP & 5 & 200 & 7523 & 0 & 2764 \\
\hline & & & 500 & 4190 & 0 & 926 \\
\hline & & & 1000 & 2427 & 0 & 381 \\
\hline \multirow[t]{3}{*}{185} & DBP & 5 & 200 & 21,039 & 0 & 14,001 \\
\hline & & & 500 & 16,968 & 0 & 10,169 \\
\hline & & & 1000 & 11,987 & 0 & 6765 \\
\hline \multirow[t]{3}{*}{1} & DBP & 10 & 200 & 2298 & 1907 & 179 \\
\hline & & & 500 & 1024 & 941 & 40 \\
\hline & & & 1000 & 539 & 516 & 11 \\
\hline \multirow[t]{3}{*}{4} & DBP & 10 & 200 & 9731 & 203 & 133 \\
\hline & & & 500 & 6338 & 6 & 30 \\
\hline & & & 1000 & 1806 & 2 & 18 \\
\hline \multirow[t]{3}{*}{8} & DBP & 10 & 200 & 4482 & 2216 & 1119 \\
\hline & & & 500 & 1806 & 1039 & 276 \\
\hline & & & 1000 & 1028 & 709 & 120 \\
\hline \multirow[t]{3}{*}{12} & DEHP & 5 & 200 & 11,004 & 0 & 2550 \\
\hline & & & 500 & 8742 & 0 & 1604 \\
\hline & & & 1000 & 5908 & 0 & 901 \\
\hline \multirow[t]{3}{*}{14} & DEHP & 5 & 200 & 10,027 & 2 & 6981 \\
\hline & & & 500 & 7603 & 2 & 4888 \\
\hline & & & 1000 & 5124 & 2 & 3040 \\
\hline \multirow{3}{*}{13} & DEHP & 10 & 200 & 11,359 & 3 & 136 \\
\hline & & & 500 & 9413 & 3 & 30 \\
\hline & & & 1000 & 6635 & 3 & 9 \\
\hline \multirow[t]{3}{*}{15} & DEHP & 10 & 200 & 6138 & 6 & 138 \\
\hline & & & 500 & 3646 & 2 & 63 \\
\hline & & & 1000 & 2153 & 2 & 21 \\
\hline \multirow{3}{*}{43} & ESBO & 5 & 200 & 9011 & 9 & 340 \\
\hline & & & 500 & 6445 & 7 & 152 \\
\hline & & & 1000 & 4105 & 5 & 70 \\
\hline \multirow[t]{3}{*}{871} & ESBO & 5 & 200 & 8849 & 23 & 5166 \\
\hline & & & 500 & 5581 & 14 & 3429 \\
\hline & & & 1000 & 3151 & 11 & 1977 \\
\hline
\end{tabular}

Filters used include threshold intensity (green plus red) values of $>200,500$, and 1000, and a fold change in gene expression of 3 . Values reported represent the number of grid locations that met both filtering conditions. Control cDNA intensity values are being retrieved as green, and the stressed cDNA intensity values are being retrieved as red. There were 13,160 potential grid locations for all chips except for chip 185 where there were 25,240 . 


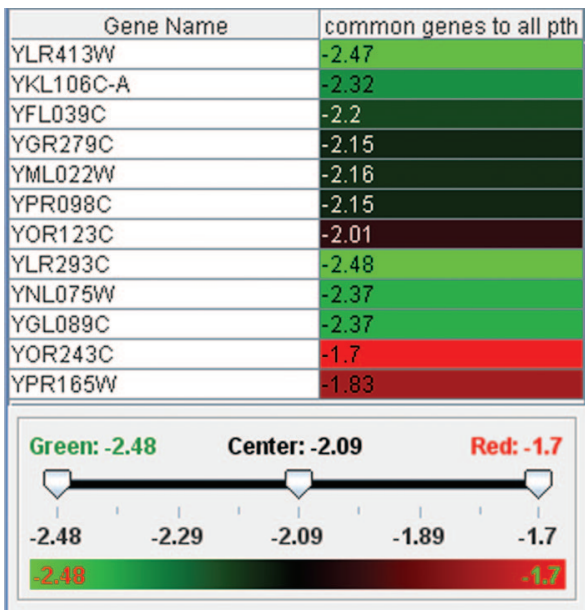

Figure 4. Gene list in MAGIC Tool's color table format. Data subjected to the analysis first passed the filtering conditions of fold change in gene expression of 3 and threshold intensity $>1000$. There were 12 genes that met the filtering criteria mentioned above and occurred in both low and high concentrations of DBP, both high and low concentrations of DEHP, and in ESBO. Expression ratios (red/ green intensities) were first averaged, and then they were transformed to $\log$ base 2 values. Finally, their dissimilarities were computed according to the MAGIC Tool tutorial. The color scale indicates the 12 genes distributed in a range from -1.70 to -2.61 of $\log$ base 2, and they represent potential repression.

that are turned off in the stressed condition) had occurred using a fold value of 3 for the ratio of red to green intensity values.

The data in Table 1 summarize the number of grid locations that contain indications of induction or repression and the total number of grid locations that were above the indicated intensity thresholds on each chip (both metagrids). Each grid location on a chip is linked to a gene name in the raw expression file, so the filtering process can be used to produce a gene list that contains potentially significant genes. The data in Table 1 confirm that changes in gene expression have occurred. Figure 4 and Table 2 show subset genes that were identified as being affected by exposure to plasticizers by using the initial data screening techniques described above. However, identifying specific genes that are strongly influenced with a high degree of certainty requires significantly more rigorous statistical analysis. Figure 5 and Table 3 show results obtained using the Significance Analysis of Microarray (SAM; 2005) program with the current data. The SAM analysis provides a list of genes similar to those identified in Table 2 . These results indicate that statistically significant up- and down-regulated genes can be identified from the microarray experiments reported here. Furthermore, the list of significant genes generated from the SAM analysis also identifies some of a group of genes with pheromone activity (Table 4), which relates to an initial hypothesis that phthalate plasticizers can function as hormone mimics (Soto et al., 1995).

Longwood students working on microarray projects are consistently eager to see that genes with known cell repair functions are identified as being significant by the microarray analysis. Additional enthusiasm develops as genes with unknown function are also identified as being significant. The genes with unknown cell function are especially interesting for students wishing to extend their research experience at Longwood University. Potential extensions include working with cell biology to identify cellular localization of the identified genes and using mathematical clustering techniques to potentially identify biological function of the indicated genes.

\section{Assessment}

Faculty accepting support from GCAT for microarray analysis projects are required to have students involved with the projects complete a preassessment and a postassessment survey (GCAT; 2006c). Assessment surveys are intended to measure knowledge gains and attitude changes connected with microarray experimentation techniques (Campbell et al., 2007 for 2005-2006 academic year responses). An independent evaluation tool is being used here to evaluate the development of broader problem-solving skills and career path evaluation and skill development related to microarray techniques.

The three students who have completed microarray research at Longwood University within the past 2 yr were asked to complete a survey of 20 statements to evaluate perceived value of their experience. This group of students is referred to as the "research group" in the remainder of the assessment discussion. The assessment attempted to evaluate perceptions related to the following areas: technical skill development, career planning, and cross-disciplinary interaction. The research group included two students majoring in biology and one student majoring in mathematics. One of the students majoring in biology graduated in 2006. The mathematics student did not participate in the hands-on laboratory portions of the projects. The overall grade point average (GPA) of the research group is 3.8. Problem-solving skills in a laboratory environment are arguably different from the problem-solving skills that students attain while completing course work. Although an intentional attempt was made to recruit enthusiastic, committed, and dependable students for the microarray research project based on demonstrated ability in organic chemistry (on the recommendation of mathematics faculty for the student majoring in mathematics), no one in the research group had prior experience with laboratory-based research projects.

A spring 2007 Longwood University genetics class, a group of 19 students majoring in biology, one of whom had performed research (in a nonmolecular biology-related field), was asked to complete the same survey as the research group as part of a laboratory activity based on the Microarrays MediaBook developed by the Institute for Science Learning (Campbell, 2005). This group of students is referred to as the "laboratory group" in the remainder of the assessment discussion. About half of the students in the laboratory group were simultaneously taking an organic chemistry class, and the group had an overall GPA of 2.9 (GPAs ranged from 2.2 to 3.5). Surveys were not graded and were not part of the class evaluation process. The surveys for the research group were not anonymous because of issues related to timing but were voluntary and were not part of any graded work. 
D. E. Walker et al.

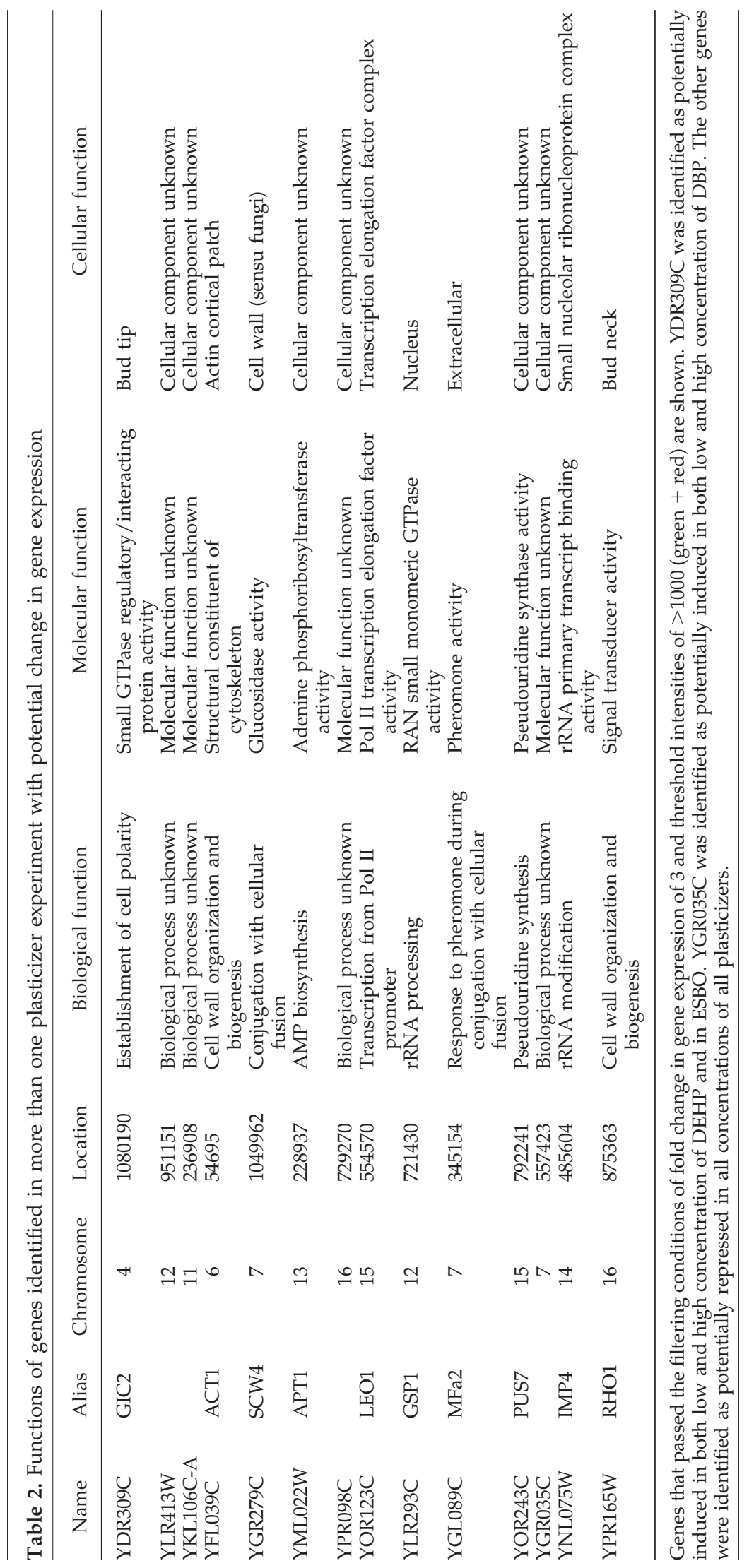




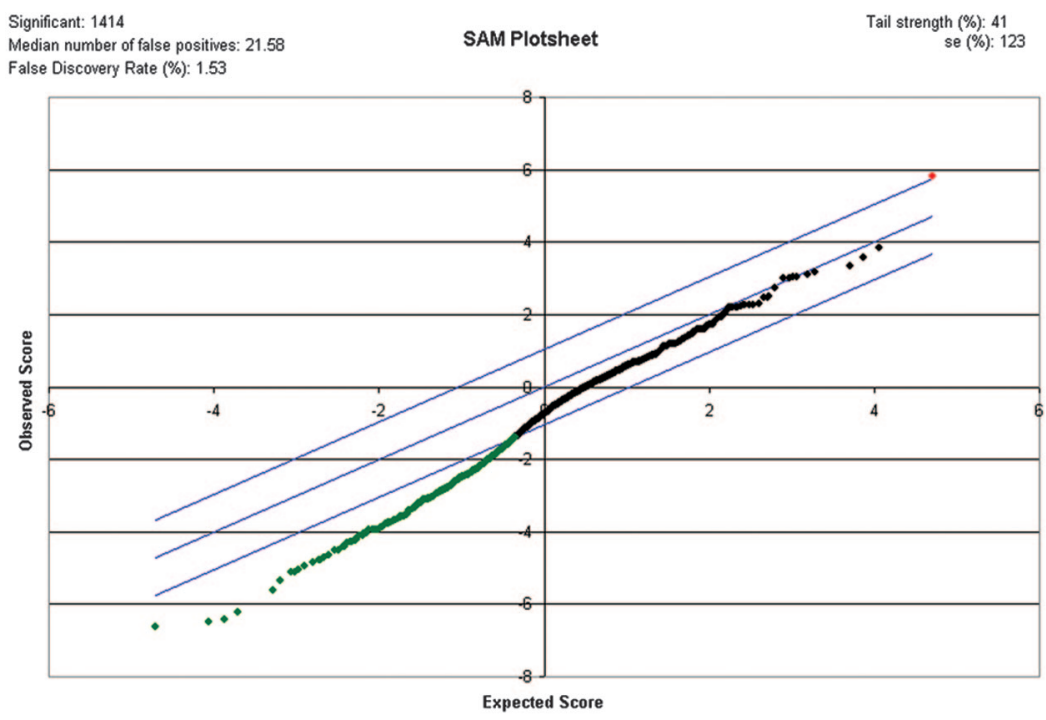

Figure 5. SAM plot result of phthalate analysis for a $\Delta$ value of 1.04 . Blue lines indicate the upper and lower limits of the $\Delta$ value. The red dot is the one positive gene identified as significant. The green dots represent a list of the 1413 negative genes identified as significant. The black dots fall within the $\Delta$ range and do not show significant changes in gene expression. The false discovery rate from the SAM analysis is $1.53 \%$.
For each assessment statement, students were asked to indicate the degree to which they either agreed or disagreed by choosing a value from 1 to 5 , where 1 indicates "strongly disagree," 2 indicates "moderately disagree," 3 indicates "neutral response," 4 indicates "moderately agree," and 5 indicates "strongly agree." In all cases, students were given the option to choose a value indicating that the question does not apply to their situation (value 0 ). The results of the student surveys for both the research group and the laboratory group are shown in Table 5. The survey statements are shown along with the average response value obtained. The number in parentheses indicates the number of students who chose a nonzero value for the statement (i.e., the number of students who thought the statement actually applied to them). This number is also the divisor used to calculate the average response value for a given statement. All survey

Table 3. SAM analysis results of significant genes

\begin{tabular}{|c|c|c|c|c|c|c|}
\hline \multirow[t]{2}{*}{ Row } & \multicolumn{6}{|c|}{ Genes } \\
\hline & Gene ID & Gene name & Score $(\mathrm{d})$ & Numerator (r) & Denominator $(\mathrm{s}+\mathrm{s} 0)$ & q value $(\%)$ \\
\hline \multicolumn{7}{|c|}{ Positive gene (l) } \\
\hline 2144 & YDR309C & YDR309C & 5.81 & 3.97 & 0.68 & 1.51 \\
\hline \multicolumn{7}{|c|}{ Negative genes (a selected group of the 1413) } \\
\hline 660 & YLR413W & YLR413W & -2.16 & -1.23 & 0.57 & 3.92 \\
\hline 1015 & YJR117W & YJR117W & -1.64 & -0.97 & 0.59 & 3.92 \\
\hline 805 & YKL106C-A & YKL106C-A & -1.67 & -1.11 & 0.67 & 3.92 \\
\hline 3401 & YFL039C & YFL039C & -1.59 & -1.22 & 0.77 & 3.92 \\
\hline 2613 & YGR279C & YGR279C & -2.53 & -1.65 & 0.65 & 3.92 \\
\hline 3139 & YML022W & YML022W & -1.30 & -0.81 & 0.62 & 3.92 \\
\hline 5480 & YGL089C & YGL089C & -1.74 & -1.06 & 0.61 & 3.92 \\
\hline 4907 & YPR098C & YPR098C & -1.23 & -0.65 & 0.53 & 3.92 \\
\hline 6507 & YOR123C & YOR123C & -1.19 & -0.87 & 0.73 & 3.92 \\
\hline 3535 & YLR293C & YLR293C & -1.68 & -1.08 & 0.65 & 3.92 \\
\hline 1438 & YKL019W & YKL019W & -1.53 & -1.06 & 0.69 & 3.92 \\
\hline 5966 & YKL209C & YKL209C & -3.13 & -1.80 & 0.58 & 3.92 \\
\hline 5480 & YGL089C & YGL089C & -1.74 & -1.06 & 0.61 & 3.92 \\
\hline 6107 & YOR243C & YOR243C & -0.88 & -0.69 & 0.78 & 3.92 \\
\hline 6101 & YOR219C & YOR219C & -4.05 & -2.35 & 0.58 & 3.92 \\
\hline
\end{tabular}

Bold genes are related to pheromone activity, and italicized genes are for $\Delta=0.8$. All other genes listed are for $\Delta=1.04$. Score (d) represents the $t$ statistic value. Numerator represents the numerator in the $t$ statistic value, and denominator represents the denominator of the $t$ statistic. The $q$ value represents the lowest false discovery rate at which a gene is called significant and is similar to the " $p$ value." The $q$ values $<5 \%$ are significant. 
Table 4. Significant genes that are known to have pheromone activity

\begin{tabular}{|c|c|c|c|c|}
\hline Gene name & Alias & Biological function & Molecular function & Cellular function \\
\hline YDL216C & RRI1 & $\begin{array}{l}\text { Adaptation to pheromone during } \\
\text { conjugation with cellular fusion }\end{array}$ & Metalloendopeptidase activity & Signalosome complex \\
\hline YDR410C & STE14 & Peptide pheromone maturation & $\begin{array}{l}\text { Protein-S-isoprenylcysteine } O \text { - } \\
\text { methyltransferase activity }\end{array}$ & Endoplasmic reticulum membrane \\
\hline YDR461W & MFA1 & $\begin{array}{l}\text { Signal transduction during } \\
\text { conjugation with cellular fusion }\end{array}$ & Pheromone activity & Soluble fraction \\
\hline YGL089C & $\mathrm{MF} \alpha 2$ & $\begin{array}{l}\text { Response to pheromone during } \\
\text { conjugation with cellular fusion }\end{array}$ & Pheromone activity & Extracellular \\
\hline YIL122W & POG1 & $\begin{array}{l}\text { Reentry into mitotic cell cycle after } \\
\text { pheromone arrest }\end{array}$ & $\begin{array}{l}\text { Specific RNA polymerase II } \\
\text { transcription factor activity }\end{array}$ & Nucleus \\
\hline YJR117W & STE24 & Peptide pheromone maturation & Metalloendopeptidase activity & $\begin{array}{l}\text { Endoplasmic reticulum membrane, } \\
\text { intrinsic protein }\end{array}$ \\
\hline YKL019W & RAM2 & Peptide pheromone maturation & Protein farnesyltransferase activity & Protein farnesyltransferase complex \\
\hline YKL178C & STE3 & $\begin{array}{l}\text { Signal transduction during } \\
\text { conjugation with cellular fusion }\end{array}$ & $\begin{array}{l}\text { Mating-type a-factor pheromone } \\
\text { receptor activity }\end{array}$ & Integral to plasma membrane \\
\hline YKL209C & STE6 & Peptide pheromone export & $\begin{array}{l}\text { ATP-binding cassette transporter } \\
\text { activity }\end{array}$ & Integral to plasma membrane \\
\hline YML057W & CMP2 & $\begin{array}{l}\text { Adaptation to pheromone during } \\
\text { conjugation with cellular fusion }\end{array}$ & $\begin{array}{l}\text { Calcium-dependent protein serine/ } \\
\text { threonine phosphatase activity }\end{array}$ & Cytoplasm \\
\hline YOR219C & STE13 & Peptide pheromone maturation & Aminopeptidase activity & Golgi apparatus \\
\hline YPL187W & $\mathrm{MF} \alpha 1$ & $\begin{array}{l}\text { Response to pheromone during } \\
\text { conjugation with cellular fusion }\end{array}$ & Pheromone activity & Extracellular \\
\hline
\end{tabular}

statements were written as having a potentially positive impact, adding value so that higher average response values represent a beneficial or positive impression for the students.

The survey responses generally indicate a positive impact on technical skill development (survey statements 1-5) for both the laboratory group and the research group. The fact that the research group's responses are more strongly positive than the laboratory group's for this set of questions is consistent with what would be expected given the inherent differences in experience gained from a research experience versus a single laboratory event. Even though statements 1-5 were not directly intended to evaluate cross-disciplinary issues, the results obtained included three questions that the mathematics student in the research group felt were applicable to her situation even though she did not perform any work in a "bench" laboratory environment. These responses further illustrate the potential value that a cross-disciplinary program offers to students in nonlaboratory degree programs.

For the survey statements related to career evaluation (statements 6-10), the responses are moderately positive for the research group and are slightly negative for the laboratory group (for all statements except 7 ). The results for the research group are less strongly positive than for statements related to skill development or to cross-disciplinary issues. There is a variety of potential reasons why the research model used throughout the microarray projects had only a minor impact on student opinions within the research group related to career evaluation. One reason may be that although career evaluation was a goal of the work, discussions related to career evaluation were intentionally not a part of the core project activities so as not to influence unduly students toward a laboratory research-based career path (the biology students involved in the research group both came to Longwood University with goals of entering a medical profession). It was hoped that students would start to draw their own inferences concerning the relationship between the work they were doing for the project and work they may choose to do in the future. The mildly positive result for the research group may be an indication that the students did start to make useful correlations on their own. The slightly negative responses for the laboratory group may be an indication that some students fail to make a connection between activities in laboratory exercises and applications of knowledge in technical careers. Higher positive responses for both groups may be obtained if discussions surrounding topics related to career development are included in the research model and in laboratory activities.

The survey responses for statements 11-15 are primarily related to cross-disciplinary issues. The results are generally strongly positive for the research group and mildly positive for the laboratory group. Students indicated both increased appreciation for another discipline as well as deeper skill development in another field. The mildly positive responses by the laboratory group were somewhat surprising given that the laboratory exercise did not intentionally include an emphasis on cross-disciplinary issues.

The last five survey statements (statements 16-20) were intended to gauge the perceived overall value of the microarray technology used within the project and the laboratory exercise. The results are generally positive for both groups with the research group being somewhat higher.

For comparison, the 2006-2007 GCAT assessment results for Longwood's laboratory group indicate that the average percentage correct across all test items for the preassessment survey was $18.2 \%$, whereas the average percentage correct on the postassessment survey was $29.8 \%$. Thus, students in 
Table 5. Results of student assessment survey

\begin{tabular}{|c|c|c|c|}
\hline Statement no. & Technical skill development & Research group ${ }^{a}$ & Laboratory group ${ }^{a}$ \\
\hline 1 & $\begin{array}{l}\text { Working with a microarray research project is having/has had a } \\
\text { positive impact on the development of my skills in a laboratory } \\
\text { environment. }\end{array}$ & $5(2)$ & $3.4(18)$ \\
\hline 2 & $\begin{array}{l}\text { Working with a microarray research project is having/has had a } \\
\text { positive impact on my ability to evaluate the results of an } \\
\text { experiment. }\end{array}$ & $4.7(3)$ & 3.3 (19) \\
\hline 3 & $\begin{array}{l}\text { Working with a microarray research project is having/has had a } \\
\text { positive impact on my ability to incorporate ideas from other } \\
\text { fields when pursuing solutions to problems. }\end{array}$ & $4.7(3)$ & $3.2(19)$ \\
\hline 4 & $\begin{array}{l}\text { Working with a microarray research project is having/has had a } \\
\text { positive impact on my ability to understand the purpose of } \\
\text { steps performed during an experimental procedure or protocol. }\end{array}$ & $5(2)$ & $3.4(19)$ \\
\hline 5 & $\begin{array}{l}\text { Working with a microarray research project is having/has had a } \\
\text { positive impact on my ability to evaluate the quality/validity of } \\
\text { the results of an experiment. }\end{array}$ & $5(3)$ & $3.4(19)$ \\
\hline \multicolumn{4}{|c|}{ Career evaluation } \\
\hline 6 & $\begin{array}{l}\text { Working with a microarray research project is having/has had a } \\
\text { positive impact on my ability to make choices related to career } \\
\text { decisions. }\end{array}$ & $3.7(3)$ & $2.7(15)$ \\
\hline 7 & $\begin{array}{l}\text { Working with a microarray research project is having/has had a } \\
\text { positive impact on my ability to evaluate potential topics for } \\
\text { research. }\end{array}$ & $4.7(3)$ & $3.2(17)$ \\
\hline 8 & $\begin{array}{l}\text { Working with a microarray research project is having/has had a } \\
\text { positive impact on my ability to feel that I am making correct } \\
\text { choices related to my career path. }\end{array}$ & $3.3(3)$ & $2.6(16)$ \\
\hline 9 & $\begin{array}{l}\text { Working with a microarray research project is having/has had a } \\
\text { positive impact on my ability to evaluate my career options. }\end{array}$ & $3.3(3)$ & $2.9(16)$ \\
\hline 10 & $\begin{array}{l}\text { Working with a microarray research project is having/has had a } \\
\text { positive impact on my ability to interact with individuals } \\
\text { during technical interviews. }\end{array}$ & $4.3(3)$ & $2.8(16)$ \\
\hline \multicolumn{4}{|c|}{ Cross-disciplinary issues } \\
\hline 11 & $\begin{array}{l}\text { Working with a microarray research project is having/has had a } \\
\text { positive impact on my appreciation of other disciplines. }\end{array}$ & $5(3)$ & $3.2(19)$ \\
\hline 12 & $\begin{array}{l}\text { Working with a microarray research project is having/has had a } \\
\text { positive impact on my learning in at least one other technical } \\
\text { field. }\end{array}$ & $5(3)$ & $3.2(18)$ \\
\hline 13 & $\begin{array}{l}\text { Working with a microarray research project is having/has had a } \\
\text { positive impact on my ability to interact with individuals in } \\
\text { alternative fields of study. }\end{array}$ & $4.3(3)$ & $3.4(17)$ \\
\hline 14 & $\begin{array}{l}\text { Working with a microarray research project is/was beneficial in } \\
\text { preparing me for participating in research/career opportunities } \\
\text { outside of Longwood University. }\end{array}$ & $4(3)$ & $3.6(18)$ \\
\hline 15 & $\begin{array}{l}\text { Working with a microarray research project is/was beneficial in } \\
\text { preparing me to evaluate other students' research at technical } \\
\text { conferences. }\end{array}$ & $4.7(3)$ & $3.1(16)$ \\
\hline \multicolumn{4}{|c|}{ Overall value of using microarray technology } \\
\hline 16 & $\begin{array}{l}\text { Features that helped me develop my problem-solving skills in } \\
\text { the laboratory while in college. }\end{array}$ & $4(2)$ & $3.3(15)$ \\
\hline 17 & $\begin{array}{l}\text { Because of working with the microarray research project, my } \\
\text { understanding of other molecular biology techniques is } \\
\text { increasing or has increased. }\end{array}$ & $4(2)$ & $3.2(18)$ \\
\hline 18 & $\begin{array}{l}\text { I value my work with microarray research at Longwood } \\
\text { University. }\end{array}$ & $5(3)$ & $3.3(18)$ \\
\hline 19 & $\begin{array}{l}\text { Without the opportunity to participate in a microarray research } \\
\text { project, I would likely not have learned about microarray in } \\
\text { college. }\end{array}$ & $4(3)$ & $3.9(19)$ \\
\hline 20 & $\begin{array}{l}\text { I feel that participating in microarray research at the } \\
\text { undergraduate level is playing/has played an important role } \\
\text { in the advancements I have made in my career thus far. }\end{array}$ & $4.3(3)$ & $3.4(17)$ \\
\hline
\end{tabular}

0 , not applicable; 1 , strongly disagree; 2 , moderately disgree; 3 , neutral; 4 , moderately agree; and 5 , strongly agree.

a Average of assessment results. Number in parentheses represents the number of students with a nonzero response. 
the laboratory group gained an average of $11.6 \%$ correct responses. This is comparable with the $10.15 \%$ average increase reported for the GCAT control group of 203 students (GCAT, 2006c). No comparative assessment data were obtained from GCAT for the research group due to the small sample size.

\section{CONCLUSIONS}

A research-based model for introducing microarray analysis to non-R1 institutions that includes the following components has been reported: selection of potential molecular biology research students based on performance in organic chemistry, use of student-driven choices for the specific avenues of research, use of trouble-shooting techniques for critical-thinking skill development, creation of a cross-disciplinary environment using familiarity with organic chemistry and data analysis as vehicles to engage students in learning within other disciplines, engagement of students as early as possible during their undergraduate experience, and use of the resources offered by GCAT as a critical component in making the research possible. The evaluation of the model's impact on three Longwood University students who have participated in various microarray projects indicates that the projects generally had a moderate to strong positive impact on 1) students' learning related to skill development within their discipline, 2) appreciation of and learning within another discipline, 3) career self-evaluation, 4) and learning related to microarray technology.

The work reported here represents an important addition to the fundamental molecular biology curriculum taught in the Biological and Environmental Science Department at Longwood University. A multidisciplinary molecular biology research environment that includes faculty and students from the departments of Chemistry and Physics and the Department of Mathematics and Computer Science was also created at Longwood University. The application of techniques illustrated by the model presented here may be potentially valuable additions to a large number of non-R1 undergraduate institutions that are in the process of incorporating microarray concepts, genomic concepts, or both into their curricula. The results of preliminary analysis of the microarray data generated by the reported work have illuminated several potential avenues for extension of the initial research project, including new projects in mathematics and in cellular biology.

\section{ACKNOWLEDGMENTS}

We especially thank the following people and organizations: 1) GCAT for support related to all aspects of performing gene expression microarray analysis; 2) Dr. Karen Bernd for helpful support while trouble-shooting RNA extraction protocols; 3) colleagues Drs. Susan Booker, Leigh Lunsford, and Melissa Zwick for helpful comments on the manuscript and William Tucker for valuable help on properly formatting figures and tables; 4) all GCAT members who individually contributed to insightful discussion through the GCAT-L listserv; and 5) Longwood student funds that provided money to purchase a dedicated computer and initial stores of reagents.

\section{REFERENCES}

Alvarez, C. J., and Wise, J. A. (2001). Activation of a cryptic 5' splice site by U1 snRNA. RNA 7, 342-350.

Arnaud, C. H. (2006). Systems biology's clinical future. C\&E News. $84,17-26$.

Caldwell, J. C., Woodruff, T. J., Morello-Frosch, R., and Axelrad, D. A. (1998). Application of health information to hazardous air pollutants modeled in EPA's cumulative exposure project. Toxicol. Ind. Health 14, 429-454.

Campbell, A. M., and University of North Carolina at Chapel Hill. (2005). Microarrays MediaBook, Chapel Hill, NC: Institute for Science Learning: Chapel Hill, NC.

Campbell, A. M., Eckdahl, T. T., Fowlks, E., Heyer, L. J., Hoopes, L.L.M., Ledbetter, M. L., and Rosenwald, A. G. (2006). Genome Consortium for Active Teaching (GCAT). Science 311, 1103-1104.

Campbell, A. M., Ledbetter, M. L., Hoopes, L.L.M., Eckdahl, T. T., Heyer, L. J., Rosenwald, A. G., Fowlks, E., Tonidandel, S., Bucholtz, B., and Gottfried, G. (2007). Genome Consortium of Active Teaching: meeting the goals of BIO2010. CBE Life Sci. Educ. 6, 109-118.

Chan, P.K.L., and Meek, M. E. (1994). Di-n-octyl phthalate: evaluation of risks to health environmental exposure in Canada. Environ. Carcinog. Ecotoxicol. Rev. C 12, 319-326.

DeRisi, J. L., Iyer, V. R., and Brown, P. O. (1997). Exploring the metabolic and genetic control of gene expression on a genomic scale. Science $278,680-686$.

Fehrenbach, E., Zieker, D., Niess, A. M., Moeller, E., Russwurm, S., and Northoff, H. (2003). Microarray technology-the future analyses tool in exercise physiology? Exerc. Immunol. Rev. 9, 58-69.

Fracasso, M. E., Franceschetti, P., Mossini, E., Tieghi, S., Perbellini, L., and Romeo, L. (1999). Exposure to mutagenic airborne particulate in a rubber manufacturing plant. Mutat. Res. 441, 43-51.

Genome Consortium for Active Teaching (GCAT) (2006a). Sending chips and retrieval of data. http://www.bio.davidson.edu/ projects/gcat/FAQ.html (accessed 20 May 2006).

GCAT (2006b). Gene lists. http:/ / www.bio.davidson.edu/projects/ gcat/GCATprotocols.html\#yeast (accessed 24 July 2006).

GCAT (2006c). Assessment tools. http://www.bio.davidson.edu/ projects/gcat/assessment/assess.html (accessed 18 December 2006).

Grigoryev, D. N., Ma, S. F., Irizarry, R. A., Ye, S. Q., Quackenbush, J., and Garcia, J. G. (2004). Orthologous gene-expression profiling in multi-species models: search for candidate genes. Genome Biol. 5, R34.

Heyer, L. J., Moskowitz, D. Z., Abele, J. A., Karnik, P., Choi, D., Campbell, A. M., Oldham, E. E., and Akin, B. K. (2005). Gene expression. MAGIC Tool: integrated microarray data analysis. Bioinformatics 21, 2114-2115.

Huang, Q., Wang, Q., Tan, W., Song, G., Lu, G., and Li, F. (2006). Biochemical responses of two typical duckweeds exposed to dibutyl phthalate. J. Environ. Sci. Health A Toxicol. Hazard. Subst. Environ. Eng. 41, 1615-1626.

Kambia, K., Dine, T., Gressier, B., Dupin-Spriet, T., Luyckx, M., and Brunet, C. (2004). Evaluation of the direct toxicity of trioctyltrimellitate (TOTM), di(2-ethylhexyl) phthalate (DEHP) and their hydrolysis products on isolated rat hepatocytes. Int. J. Artif. Organs 27 971-978.

Kerr, M. K., Afshari, C. A., Bennett, L., Bushel, P., Martinez, J., Walker, N. J., and Churchill, G. A. (2002). Statistical analysis of a gene expression microarray experiment with replication. Stat. Sin. $12,203-217$ 
Mahood, I. K., Hallmark, N., McKinnel, C., Walker, M., Fisher, J. S., and Sharpe, R. M. (2005). Abnormal Leydig Cell aggregation in the fetal testis of rats exposed to di (n-butyl) phthalate and its possible role in testicular dysgenesis. Endocrinology 146, 613-623.

Meek, M. E., and Chan, P.K.L. (1994). Bis(2-ethylhexyl) phthalate: evaluation of risks to health environmental exposure in Canada. J. Environ. Sci. Health C Environ. Carcinog. Ecotoxical. Rev. C 12, 179-194.

Mikula, P., Svobodova, Z., and Smutna, M. (2005). Phthalates: toxicology and food-safety-a review. Czech J. Food Sci. 23, 217-223.

Molhave, L., Schneider, T., Kjaergaard, S. K., Larsen, L., Norn, S., and Jorgensen, O. (2000). House dust in seven Danish offices. Atmos. Environ. 34, 4767-4779.

Munksgaard, E. C. (2004). Leaching of plasticizers from temporary denture soft lining materials. Eur. J. Oral Sci. 112, 101-104 (erratum in: Eur J Oral Sci. (2004). 112, 205).

National Institute for Science Education (2003). National Institute for Science Education: college level one: innovations in stem education. http://www.wcer.wisc.edu/nise/cl1 (accessed 16 October, 2006).

Roberts, D. R. (1983). National Institute for Occupational Safety and Health/Environmental Protection Agency Interagency Agreement for the Assessment of Human Health Effects from Exposure to di-2-(ethylhexyl) phthalate. National Institute for Occupational Safety and Health Report, Order No. PB84-182047, 1-17.

Saillenfait, A. M., Sabate, J. P., and Gallissot, F. (2006). Developmental toxic effects of di-isobutyl phthalate, the methyl-branched ana- logue of di-n-butyl phthalate, administered by gavage to rats. Toxicol. Lett. 165, 39-46.

Shahin, M. M., and Von Borstel, R. C. (1977). Mutagenic and lethal effects of alpha-benzene hexachloride, dibutyl phthalate and trichloroethylene in Saccharomyces cerevisiae. Mutat. Res. 48, 173-180.

Significance Analysis of Microarray (SAM) (2005). http://wwwstat.stanford.edu/ tibs/SAM/index.html (accessed 20 May 2007).

Sobarzo, C. M., Lustig, L., Ponzio, R., and Denduchis, B. (2006). Effect of di-(2-ethylhexyl) phthalate on N-cadherin and catenin protein expression in rat testis. Reprod. Toxicol. 22, 77-86.

Soto, A. M., Sonnenschein, C., Chung, K. L., Fernandez, M. F., Olea, N., and Serrano, F. O. (1995). The E-SCREEN assay as a tool to identify estrogens: an update on estrogenic environmental pollutants. Environ. Health Perspect. 103, 113-122.

Tanner, K., Chatman, L. S., and Allen, D. (2003). Approaches to cell biology teaching: cooperative learning in the science classroombeyond students working in groups. Cell Biol. Educ. 2, 1-5.

Tseng, G. C., Oh, M. K., Rohlin, L., Liao, J. C., and Wong, W. H. (2001). Issues in cDNA microarray analysis: quality filtering, channel normalization, models of variations and assessment of gene effects. Nucleic Acids Res. 29, 2549-2557.

Tusher, V., Tibshirani, R., and Chu, C. (2001). Significance analysis of microarrays applied to ionizing radiation response. Proc. Natl. Acad. Sci. USA 98, 5116-5121.

Uno, E. G. (1990). Inquiry in the classroom. Bioscience 40, 841-844.

Verma, C. N., and Singh, R. K. (2001). Stress-Inducible DNA repair in Saccharomyces cerevisiae. J. Environ. Pathol. Toxicol. Oncol. 20, 1-7. 